
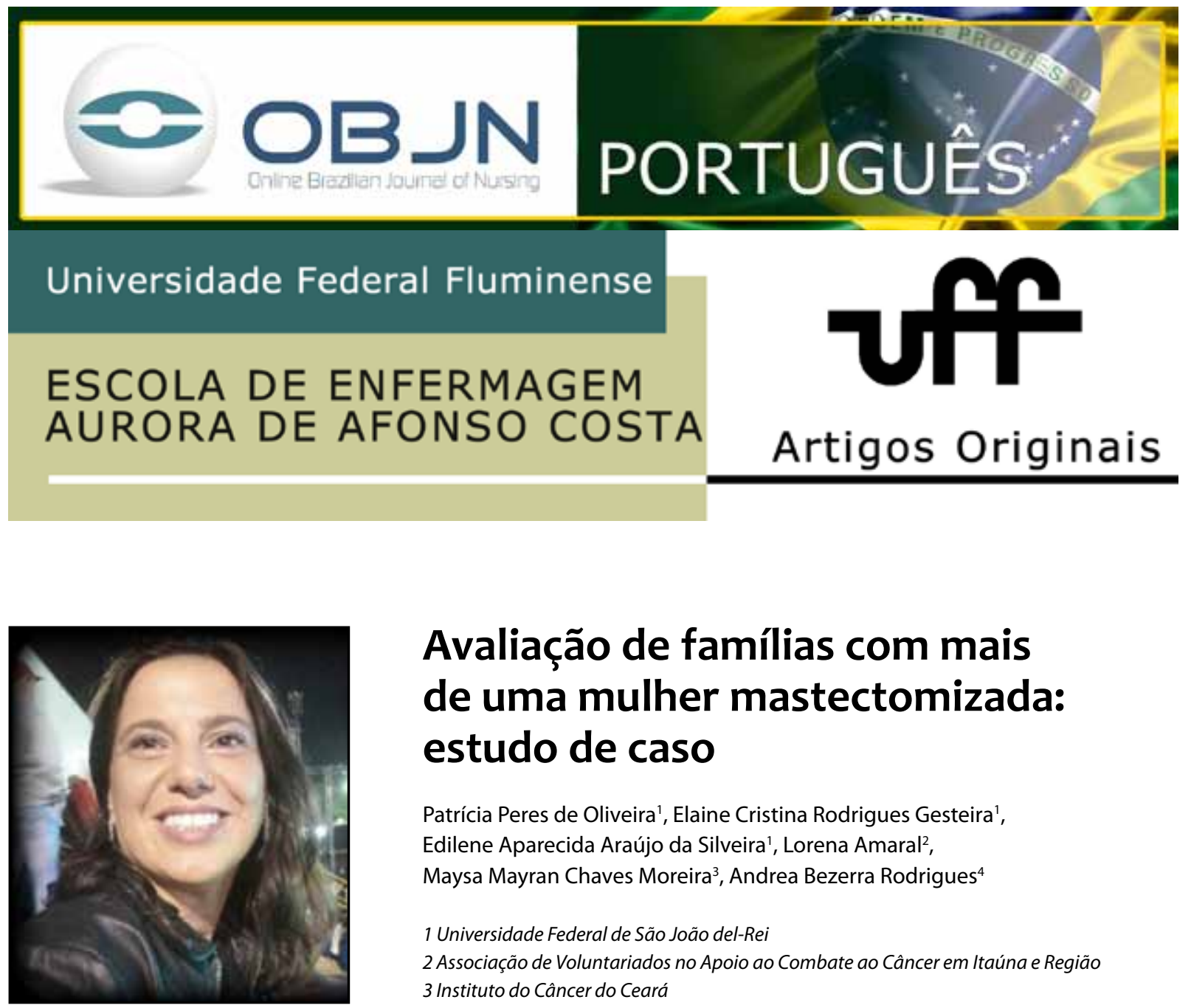

\title{
Avaliação de famílias com mais de uma mulher mastectomizada: estudo de caso
}

\author{
Patrícia Peres de Oliveira', Elaine Cristina Rodrigues Gesteira' ${ }^{1}$ \\ Edilene Aparecida Araújo da Silveira', Lorena Amaral ${ }^{2}$, \\ Maysa Mayran Chaves Moreira ${ }^{3}$, Andrea Bezerra Rodrigues ${ }^{4}$ \\ 1 Universidade Federal de São João del-Rei \\ 2 Associação de Voluntariados no Apoio ao Combate ao Câncer em Itaúna e Região \\ 3 Instituto do Câncer do Ceará \\ 4 Universidade Federal do Ceará
}

\section{RESUMO}

Objetivo: avaliar a estrutura, o desenvolvimento e a funcionalidade de famílias com mais de uma mulher com neoplasia maligna da mama e mastectomizada. Método: estudo qualitativo com base teórica nas categorias estrutural, desenvolvimental e funcional, propostas pelo modelo Calgary e com estudo de caso como estratégia metodológica. Os dados foram coletados por meio de visitas domiciliares junto a 10 famílias com mulheres mastectomizadas, no período de agosto de 2014 a fevereiro de 2015. Resultados: subsistemas conflituosos estiveram presentes apenas em duas famílias e todas apresentaram em sua rede de apoio elementos oriundos de outros sistemas que não o familiar, como vizinhos e instituições de saúde. No processo de assistência, o vínculo estabelecido, o apoio e o acompanhamento frequentes contribuíram para amenizar algumas dificuldades. Conclusão: acredita-se que o modelo Calgary possibilitou uma visão ampliada da família, compreensão das relações internas e externas, e busca de equilíbrio entre as fragilidades e fortalezas.

Descritores: Família; Neoplasias; Enfermagem; Saúde da Mulher. 


\section{INTRODUÇÃO}

A estrutura familiar se alicerça sobre as relações emocionais e sociais, a quem as pessoas pertencentes a ela recorrem em momentos de necessidade e, sobretudo, compartilham momentos felizes, mais do que relações de parentesco. Por fim, o que firma um grupo de indivíduos como família é a relação de apoio emocional, financeiro, educacional ou social entre seus integrantes. Deste modo, é a principal fonte de esteio das pessoas na contemporaneidade e, quando algum de seus integrantes apresenta-se fragilizado por qualquer desequilíbrio, ela necessita ser fortalecida na sua integridade ${ }^{(1-2)}$.

A família, comumente, não está organizada para enfrentar o adoecimento e suportar a angústia de algum de seus membros ${ }^{(2)}$. No caso de um diagnóstico de neoplasia maligna da mama, o efeito é ainda mais devastador: seja pelo temor às mutilações e os possíveis efeitos colaterais advindos dos tratamentos, seja pelo impacto emocional e psicossocial ${ }^{(3)}$, principalmente quando mais de uma mulher adoece devido a essa enfermidade em uma mesma unidade familiar.

Um estudo de base populacional apontou que a história familiar é um fator de risco para o câncer de mama, sendo, aproximadamente, duas vezes maior para parentes de primeiro grau em comparação com os controles da população geral $^{(4)}$.

Destarte, a família exerce um papel primordial na vida das mulheres com câncer de mama, oferecendo sustentáculo, ajudando-as a passarem pelo diagnóstico da doença e a superarem os transtornos advindos (como os tratamentos), garantindo uma vida mais adaptada, menos estressante e com perspectivas de cura ${ }^{(5)}$.

Por se tratar de uma doença crônica, o tratamento será ao longo da vida. Para que ele seja bem sucedido, os familiares, desde a ocasião da descoberta, precisarão conhecer as possíveis alterações advindas dos tratamentos, os sinais das complicações, bem como atuar de forma assertiva nas possíveis intercorrências ${ }^{(4-5)}$. Dessa forma, a comoção que a doença oncológica causa na família e as formas de enfrentamento são particulares em cada unidade familiar, pois têm valores, crenças, histórias e rotinas diferentes ${ }^{(5-6)}$.

Os profissionais, com base nas investigações realizadas, necessitam usar seus conhecimentos sobre cada família a fim de garantir uma assistência holística, de forma a relacionar fatores biológicos, sociais e espirituais, preparando a partir disso o melhor cuidado ${ }^{(1,3)}$.

Diante desse contexto, optou-se por utilizar o Modelo Calgary de Avaliação da Família (MCAF), que permite um espectro expandido abarcando relações internas, externas, fragilidades e fortalezas. O MCAF constitui-se de uma estrutura multidimensional que propõe avaliar a família e adquirir conhecimentos e habilidades para possíveis intervenções necessárias. Seu uso proporciona entender o funcionamento e a dinâmica familiares de forma interacional, e proporciona a avaliação dos seus elementos e a observação das mudanças em sua dinâmica ${ }^{(2,7)}$.

No Brasil, o MCAF tem sido pouco frequente na abordagem de famílias de adultos com doenças oncológicas, sendo mais empregado em pesquisas com crianças, adolescentes, idosos e na área de saúde mental. A utilização deste modelo permite ao enfermeiro conhecer a família em seu contexto e identificar suas necessidades, assim como opções de assistência particulares a sua condição.

A relevância desta pesquisa é manifestada por se tratar de um tema importante e pela lacuna em torno da temática de avaliação de famílias com mais de uma mulher com neoplasia maligna da mama (evidenciada ao realizar busca na literatura de enfermagem), além da neoplasia maligna da mama ser dos cânceres 
mais frequentes entre as mulheres, tanto no Brasil quanto no mundo ${ }^{(4)}$.

Diante do exposto, surgiram os seguintes questionamentos: como é a estrutura e o funcionamento da família com mais de uma mulher com neoplasia de mama submetida à mastectomia? Qual o vínculo afetivo entre seus membros?

Para respondê-las, determinou-se como objetivo avaliar a estrutura, o desenvolvimento e a funcionalidade de famílias com mais de uma mulher com neoplasia maligna de mama e mastectomizada.

\section{MÉTODO}

Trata-se de um estudo exploratório-descritivo e qualitativo. Utilizaram-se os referenciais do estudo de caso e as premissas do Modelo Calgary de Avaliação da Família, respectivamente, metodológico e teórico.

O MCAF é um modelo multiestrutural formado por três categorias fundamentais: estrutural, de desenvolvimento, funcional e suas múltiplas subcategorias ${ }^{(7)}$ que permitem juntar elementos para dar subsídio e direcionar o cuidado junto a família(1-2), representado na

\section{Figura 1.}

Torna-se imperativo explanar que é função de cada enfermeiro eleger as subcategorias desse modelo a serem exploradas. Assim, nem todas as subcategorias são avaliadas em um primeiro encontro, e algumas nem sempre serão exploradas $^{(1,7)}$.

A categoria estrutural compreende a estrutura da família, ou seja, quem faz parte dela, qual é o vínculo afetivo entre seus elementos em comparação com as pessoas de fora, e qual é o seu contexto ${ }^{(2,7)}$. Três aspectos da estrutura familiar podem ser verificados: estrutura interna, estrutura externa e contexto, com suas subcategorias $^{(6)}$, descritas na Figura 1.
Utilizam-se dois instrumentos para esquematizar as estruturas internas e externas da família: o genograma e o ecomapa ${ }^{(1-2,7)}$. O genograma é uma representação gráfica da estrutura familiar interna ${ }^{(7)}$. O ecomapa é um diagrama das relações viventes ou não entre a comunidade e a família, que permite estimar apoios sociais e redes disponíveis ${ }^{(1,7)}$.

A categoria de desenvolvimento faz referência à mudança progressiva da história da família durante as etapas do ciclo de vida: sua história, o fluxo de vida, o crescimento, o nascimento e a morte ${ }^{(2)}$.

A categoria funcional refere-se à maneira como as pessoas da família interagem. Pode ser explorado o aspecto do funcionamento instrumental, que está relacionado às atividades da vida diária, e o aspecto do funcionamento expressivo, referente a modos de comunicação, solução de problemas, crenças, papéis, regras e alianças ${ }^{(2,7)}$.

O estudo de caso trata-se de um método amplo que permite ser aplicado a uma variedade de problemas. Pode ser utilizado em diversas áreas de pesquisa para proporcionar maior conhecimento e envolvimento do pesquisador com uma situação real observada ${ }^{(8)}$.

Inicialmente, as famílias foram selecionadas com o auxílio de uma informante-chave (key informants), ou seja, profissional de saúde que conhece as participantes do estudo ${ }^{(9)}$. Neste caso, uma enfermeira de uma entidade filantrópica localizada em Minas Gerais, sem fins lucrativos, cujo objetivo é prestar assistência a pessoas com câncer (AVACCI-Associação de Voluntariados no Apoio ao Combate ao Câncer em Itaúna e Região). A continuidade da seleção deu-se por meio da técnica em cadeias (snowball) ${ }^{(9)}$, isto é, a partir da identificação e da localização de uma família com determinadas características adotadas como critérios de inclusão. Essas famílias entrevistadas também se constituem 
Figura 1 - Representação esquemática do Modelo Calgary de Avaliação de Famílias ${ }^{(7)}$. Divinópolis, 2015.

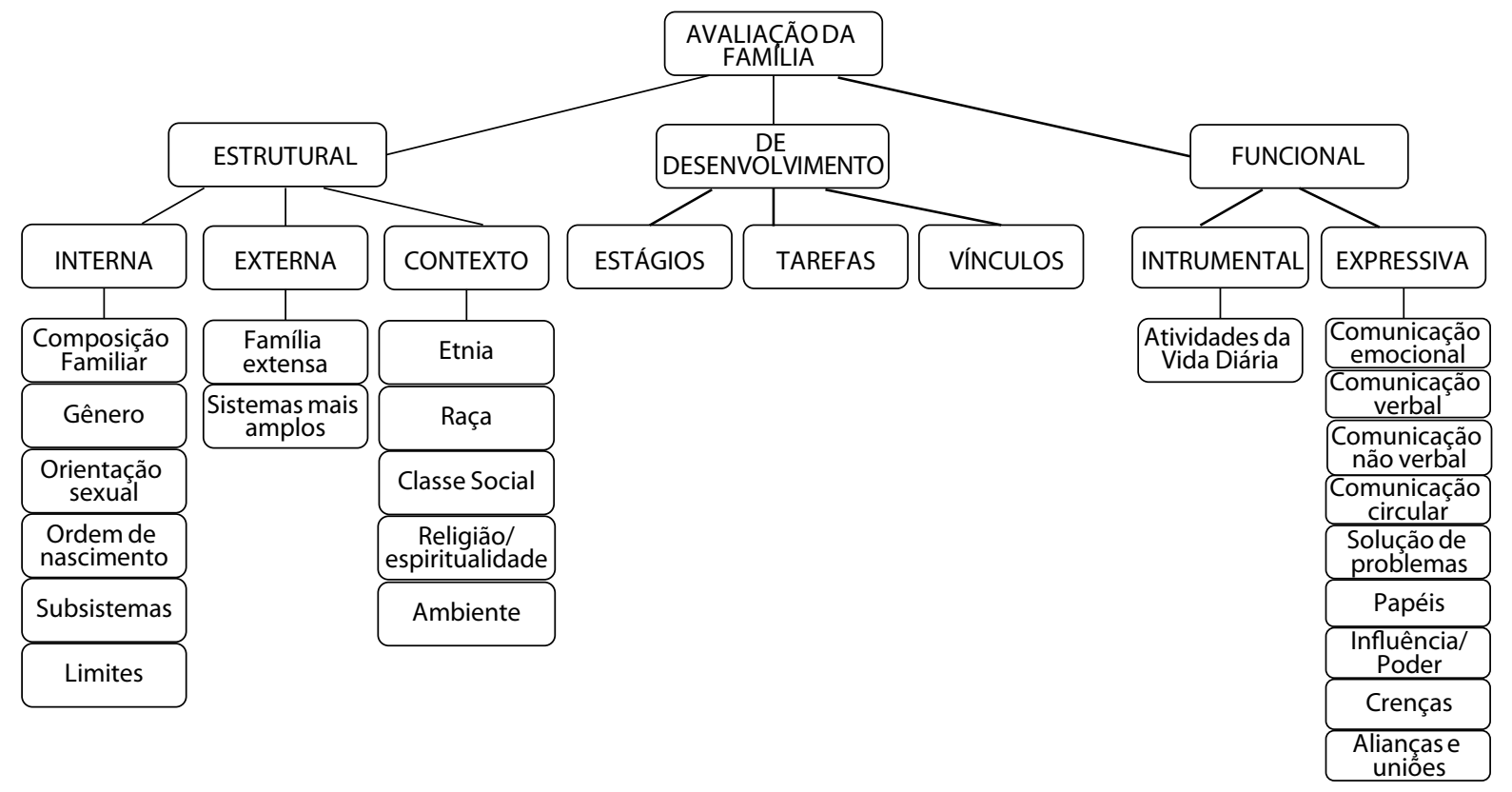

Fonte: Modelo Calgary de Avaliação de Famílias ${ }^{(7)}$.

em informantes para a identificação de outros participantes com as mesmas características para serem incluídos na investigação, sendo o processo repetido sucessivamente, a fim de identificar o maior número de famílias que possam contribuir para a realização do estudo ${ }^{(8)}$.

Primeiramente, se fez um contato informal, a fim de verificar a disponibilidade dos membros das famílias para fazer parte da pesquisa; posteriormente, cada entrevista foi marcada na residência de cada família, com data e horário escolhidos pelos participantes. As duas primeiras famílias viviam no mesmo município; as outras oito residiam em diferentes cidades de Minas Gerais, não estabelecendo entre si nenhum tipo de vínculo de parentesco.

Com base em amostragem de conveniência, adotaram-se como critério de seleção: famílias com pelo menos duas mulheres, parentes de primeiro grau (mãe e filha/s ou irmãs), mas que não necessariamente vivessem na mesma residência; que tivessem passado por tratamento para câncer de mama, incluindo a mastectomia; uma das mulheres ainda estar em tratamento adjuvante na época da pesquisa; pelo menos uma dessas mulheres estar viva. Excluíram-se famílias de mulheres mastectomizadas que não tinham disponibilidade pessoal para participar dos encontros, em qualquer momento da realização dessa pesquisa e, incapacidade de compreender e/ou responder as questões propostas por deficiência intelectual.

Realizado por meio de quatro encontros com cada família estudada, o estudo aconteceu no período de agosto de 2014 a fevereiro de 2015. A primeira entrevista teve por objetivo apresentar os aspectos éticos e legais e convidar os participantes para realização da pesquisa. $\mathrm{Na}$ segunda visita foram realizadas entrevistas com questões semiestruturadas, guiadas pelo MCAF, gravadas após autorização, com duração média de 60 minutos. Logo depois, construíram-se o genograma e o ecomapa com participação da família, a fim possibilitar análise e atender aos objetivos do estudo. Nas terceira e quarta visitas foram realizadas discussões e considerações 
sobre o genograma e o ecomapa e orientações específicas, quando necessário, para cada situação vivenciada pela família.

Para a análise dos elementos após a coleta das informações e transcrição na íntegra das entrevistas, utilizou-se como estratégia a análise temática, forma de reconhecimento de padrões dentro dos dados, em que os temas que emergem se formam em categorias ${ }^{(10-11)}$. Esta avaliação possui distintas formas de abordagem, como a dedutiva, baseada em modelos de códigos previamente determinados (template); e a indutiva, conduzida pelos dados. Neste estudo, o método escolhido foi um modelo híbrido, que agrupa tanto a dedutiva quanto a indutiva ${ }^{(10)}$. Assim, primeiramente analisam-se os dados indutivamente, originando códigos e temas iniciais, e posteriormente aplica-se o template. Nesta pesquisa utilizou o Modelo Calgary, com a meta de identificar unidades de texto significativas também de forma dedutiva ${ }^{(10)}$. Ao final, foram obtidos dados dentro das categorias estrutural, desenvolvimental ou funcional de avaliação propostas pelo MCAF.

Foi mantido o anonimato dos participantes por meio da adoção da letra $E$, seguida pelo número sequencial das entrevistas, além da letra $F$, acompanhada pelo número da família. Participaram 31 integrantes de 10 famílias: cinco maridos, 14 filhos e 12 mulheres mastectomizadas (uma integrante com câncer de mama das famílias 1, 3 , $4,6,7,8,9$ e 10 e duas integrantes com neoplasia maligna de mama das famílias 2 e 5).

Ressalta-se que, embora nem todos os integrantes das famílias tenham participado da pesquisa, o enfoque foi a unidade familiar. Desta forma, todos os participantes foram convidados a observar sua família, conforme preconiza o referencial $M \mathrm{MCAF}^{(7)}$.

O desenvolvimento do estudo ocorreu em conformidade com os preceitos éticos. O projeto foi aprovado pelo Comitê de Ética e Pesquisa da
Universidade Federal de São João del-Rei, conforme CAAE 28929914.5.0000.5545 e protocolo número 620.273. Para preservar a identidade, os sujeitos foram identificados com nomes fictícios e as famílias representadas por F1, F2, F3 e assim por diante.

\section{RESULTADOS}

A análise dos dados será apresentada conforme as categorias propostas pelo modelo Calgary.

\section{Avaliação estrutural}

Em relação à estrutura interna, cinco eram do tipo nuclear (F1, F3, F6, F8 e F9), composta pelo casal e filhos, sendo duas reconstituídas (F3 e F9) com pessoas em segundo casamento. Duas famílias eram do tipo estendida (F2 e F5), as outras três eram monoparentais (F4, F7 e F10), conforme demonstra o Quadro 1.

A idade dos participantes das 10 famílias nos quatro encontros variou entre 18 e 59 anos (média de 35,1 anos). Em relação ao número de integrantes, observou-se que eram famílias constituídas, em sua maioria, por até cinco sujeitos e nenhum idoso. No tocante aos membros de primeiro grau com câncer de mama, identificaram-se três famílias com irmãs mastectomizadas (F2, F6 e F10), quatro famílias com filha e mãe com essa doença (F1, F5, F7 e F8) e outras três participantes com irmã e mãe com a enfermidade (F3, F4 e F9); dessas 23 mulheres, cinco mastectomizadas, de famílias diferentes, faleceram devido a essa neoplasia maligna ( $F 1$, F3, F4, F8 e F9).

O impacto do óbito sobre as famílias foi grande na época do falecimento de suas mães, principalmente na Família 1, devido ao momento do ciclo vital em que ocorreu: dois 


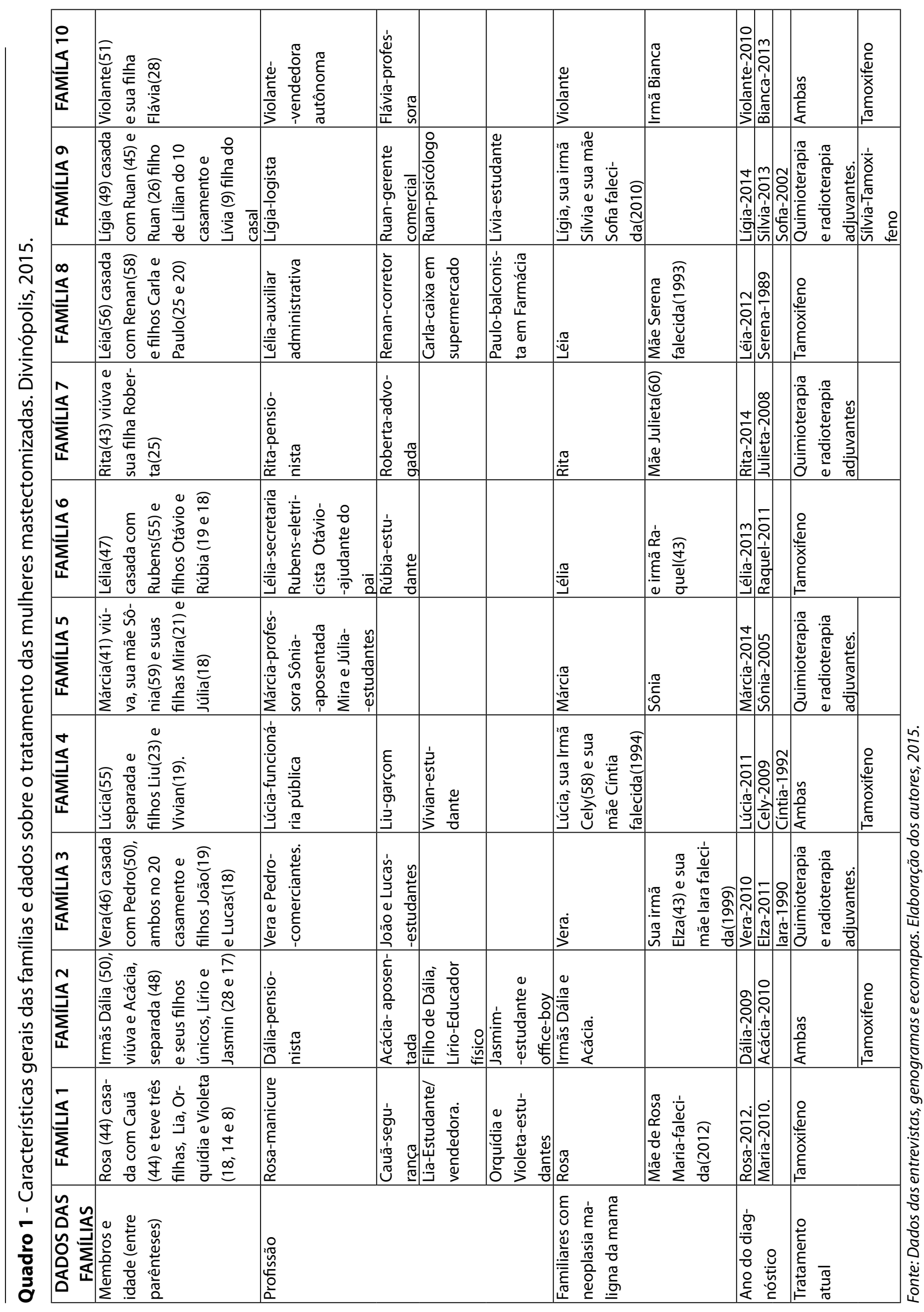

Oliveira PP, Gesteira ECR, Silveira EAA, AmaralL, Moreira MMC, Rodrigues AB. Evaluation of families with two or more mastec- 
meses após o diagnóstico, Rosa tinha realizado mastectomia e fazia quimioterapia e radioterapia adjuvantes; sua filha mais velha relatou ter medo diariamente de uma recidiva levá-la a óbito, como ocorreu com sua avó. Na Família 4, o membro caçula relatou o mesmo temor, pois sua avó faleceu de câncer de mama com a mesma idade de sua mãe.

Os subsistemas identificados na avaliação estrutural interna referiram-se a relações entre marido e mulher, pais e filhos, avó e neto, mãe e filha, entre outros; sendo estes, em sua maioria, em prol da manutenção da unidade familiar e do desenvolvimento dos cuidados e apoio a mulher mastectomizada. Os laços familiares foram fortalecidos após o advento do câncer em todas as famílias. Subsistemas conflituosos estiveram presentes nas Famílias 2 e 3. Na Família 2, em muitos momentos, houve relação conflituosa entre as irmãs, ambas em tratamento adjuvante com tamoxifeno, devido à diferença na personalidade e modo de vida. Nos momentos de estresse procuram a irmã caçula (Paula), com quem mantêm uma forte relação e é uma referência para toda a família desde a morte dos pais.

Na Família 3, o relacionamento entre o pai e o filho caçula assinalou para uma interação pouco afetuosa, com conversas agressivas e falta de controle sobre os comportamentos do adolescente, que passava mais de um dia fora de casa usando substâncias psicoativas. Entretanto, o subsistema do casal (pai e mãe), encontrava articulado, com expressão de afeto e cumplicidade durante as quatro visitas domiciliares.

Dentre os limites observados na avaliação estrutural interna, o impacto do diagnóstico de câncer foi sentido tanto pela mulher como por seus familiares, não somente pela gravidade da doença, mas por tudo que já vivenciaram. Com isso, todos os participantes revelaram esconder seus sentimentos, choros, medos e incertezas. A fim de demonstrarem força, não falavam sobre a doença, principalmente com a mulher enferma, evitando demonstração de desânimo e externalização de emoções.

No tocante à estrutura externa, verificou-se que todas as famílias dispunham de múltiplos elementos do suprasistema familiar - amigos, vizinhos, parentes, igreja, ambiente de trabalho, serviços de saúde de atenção primária, secundária e terciária -, configurando uma rede social e de apoio. Cabe ressaltar que todos os membros da família, quando necessitam de atendimento no nível terciário, são encaminhados para a capital do estado onde residem. Afirmaram que seguem corretamente todas as orientações dos profissionais de saúde e que os atendimentos, embora demorados, são de qualidade, conforme se observa no Quadro 2.

No que tange à avaliação estrutural de contexto, observou-se que a classe social e a condição financeira não influenciaram a qualidade do cuidado dispensado às mulheres mastectomizadas. Duas famílias (F3 e F9) recebiam acima de 10 salários mínimos, uma família com remuneração de cinco salários mínimos (F1), e as outras sete entre seis e dez salários mínimos. Em relação à moradia, oito famílias residiam em casa própria; a Família 2 morava em uma casa cedida por um de seus irmãos e a Família 4 pagava aluguel. Quanto à ocupação, observou-se que duas mulheres eram pensionistas e outras duas aposentadas, o restante realizava atividades laborais. No tocante à escolaridade dos membros das famílias, duas crianças cursavam o ensino fundamental, seis adolescentes frequentavam o ensino médio, três estavam no ensino superior, seis integrantes relataram ter o ensino fundamental completo, 12 tinham o ensino médio completo e oito adultos tinham o ensino superior completo.

No que diz respeito à subcategoria religião e espiritualidade, a busca por suporte espiritual foi relatada pelas mulheres enfermas e por vá- 


\section{Quadro 2}

\begin{tabular}{|c|c|c|c|c|c|c|c|c|c|c|}
\hline $\begin{array}{l}\text { INTERA- } \\
\text { ÇÕES } \\
\text { SOCIAIS }\end{array}$ & $\begin{array}{c}\text { FAMÍLIA } \\
1\end{array}$ & $\begin{array}{c}\text { FAMÍLIA } \\
2\end{array}$ & $\begin{array}{c}\text { FAMÍLIA } \\
3\end{array}$ & $\begin{array}{c}\text { FAMÍLIA } \\
4\end{array}$ & $\begin{array}{c}\text { FAMÍLIA } \\
5\end{array}$ & $\begin{array}{c}\text { FAMÍLIA } \\
6\end{array}$ & $\begin{array}{c}\text { FAMÍLIA } \\
7\end{array}$ & $\begin{array}{c}\text { FAMÍLIA } \\
8\end{array}$ & $\begin{array}{c}\text { FAMÍLIA } \\
9\end{array}$ & $\begin{array}{c}\text { FAMÍLA } \\
10\end{array}$ \\
\hline \multirow{3}{*}{$\begin{array}{l}\text { Subsiste- } \\
\text { mas }\end{array}$} & $\begin{array}{l}\text { Pais de } \\
\text { Cauã }\end{array}$ & $\begin{array}{l}\text { Sete } \\
\text { irmãos }\end{array}$ & Irmãs & $\begin{array}{l}\text { Amiga de } \\
\text { Lúcia }\end{array}$ & Tias & Pais & Mãe & $\begin{array}{l}\text { Pais de } \\
\text { Renan }\end{array}$ & Imãos & $\begin{array}{l}\text { Irmãos } \\
\text { Cunha- } \\
\text { das }\end{array}$ \\
\hline & $\begin{array}{l}\text { Oito } \\
\text { irmãos } \\
\text { e pai de } \\
\text { Rosa. }\end{array}$ & $\begin{array}{l}\text { Sobri- } \\
\text { nhos. }\end{array}$ & $\begin{array}{l}\text { Mãe de } \\
\text { Pedro }\end{array}$ & Pai & Irmãs & & Amiga & & & \\
\hline & & & $\begin{array}{l}\text { Amigo } \\
\text { de Lucas }\end{array}$ & Irmãos & $\begin{array}{l}\text { Amiga de } \\
\text { Márcia }\end{array}$ & & Irmã & & & \\
\hline \multirow{7}{*}{$\begin{array}{l}\text { Sistemas } \\
\text { mais } \\
\text { amplos }\end{array}$} & Amigos & AVACCI & Amigos & Igreja & $\begin{array}{l}\text { Hospital } \\
\text { em BH }\end{array}$ & Amigos & Amigos & Amigos & Amigos & Amigos \\
\hline & AVACCI & Amigos & $\begin{array}{l}\text { Hospital } \\
\text { em BH }\end{array}$ & Amigos & Amigos & Igreja & Comadre & $\begin{array}{l}\text { Hospital } \\
\text { em } \mathrm{BH}\end{array}$ & Vizinhos & Clube \\
\hline & Vizinhos & Vizinhos & Clube & Comadre & Igreja & UBS & $\begin{array}{l}\text { Hospital } \\
\text { em BH }\end{array}$ & Igreja & Igreja & Trabalho \\
\hline & Igreja & Igreja & Escola & Vizinhos & & Escola & Trabalho & Escola & UBS & Igreja \\
\hline & UBS & UBS & & Escola & & Trabalho & Igreja & & Escola & \\
\hline & Escola & & & Trabalho & & & & & Trabalho & \\
\hline & Trabalho & & & & & & & & & \\
\hline \multirow{2}{*}{$\begin{array}{l}\text { Contatos } \\
\text { signifi- } \\
\text { cativos/ } \\
\text { apoiado- } \\
\text { res }\end{array}$} & $\begin{array}{l}\text { Irmã } \\
\text { (Vilma) }\end{array}$ & $\begin{array}{l}\text { Irmã } \\
\text { caçula } \\
\text { (Paula) }\end{array}$ & $\begin{array}{l}\text { Irmã } \\
\text { (Elza) }\end{array}$ & $\begin{array}{l}\text { Amiga de } \\
\text { Lúcia }\end{array}$ & $\begin{array}{l}\text { Irmã de } \\
\text { Sônia }\end{array}$ & Mãe & $\begin{array}{l}\text { Mãe Ju- } \\
\text { lieta(60) }\end{array}$ & Marido & $\begin{array}{l}\text { Irmã } \\
\text { Sílvia }\end{array}$ & $\begin{array}{l}\text { Irmã } \\
\text { Bianca }\end{array}$ \\
\hline & & & & & $\begin{array}{l}\text { Amiga de } \\
\text { Márcia }\end{array}$ & & Amiga & & & \\
\hline \multirow{3}{*}{$\begin{array}{l}\text { Ambien- } \\
\text { tes que } \\
\text { mais } \\
\text { frequen- } \\
\text { tam }\end{array}$} & Igreja & $\begin{array}{l}\text { Dália-via- } \\
\text { gem com } \\
\text { amigas }\end{array}$ & Clube & Igreja & Igreja & Igreja & $\begin{array}{l}\text { Casa de } \\
\text { vizinhos }\end{array}$ & $\begin{array}{l}\text { Casa de } \\
\text { amigos }\end{array}$ & $\begin{array}{l}\text { Casa de } \\
\text { amigos }\end{array}$ & $\begin{array}{l}\text { Casa de } \\
\text { amigos }\end{array}$ \\
\hline & Festas & $\begin{array}{l}\text { Casa de } \\
\text { amigas. }\end{array}$ & Festas & $\begin{array}{l}\text { Casa de } \\
\text { amigos }\end{array}$ & $\begin{array}{l}\text { Casa de } \\
\text { amigos }\end{array}$ & $\begin{array}{l}\text { Casa de } \\
\text { amigos }\end{array}$ & & Igreja & Igreja & Viagem \\
\hline & $\begin{array}{l}\text { Sítio dos } \\
\text { pais de } \\
\text { Cauã }\end{array}$ & & Viagens & & & & & & & \\
\hline
\end{tabular}

Fonte: Dados das entrevistas, genogramas e ecomapas. Elaboração dos autores, 2015. 
rios familiares. O suporte espiritual e a fé deram força para ultrapassar os obstáculos e conforto por meio da manutenção da esperança, além de auxiliar na promoção do bem-estar das famílias. Na subcategoria ambiente, verificou-se que todas as famílias viviam em bairros com condições sociais e sanitárias satisfatórias.

Avaliação de desenvolvimento

Em relação aos estágios da vida familiar, duas famílias encontravam-se no estágio de "famílias com filhos adolescentes" (F3 e F6), uma família convivia com adolescentes e criança (F1), outra família convivia com jovem adulto solteiro e criança (F9), três coexistiam com adultos jovens solteiros (F7, F8 e F10), outras duas conviviam com jovem adulto solteiro e adolescente (F2 e F4) e em uma família coabitavam avó, filha adulta jovem solteira e adolescente (F5).

Neste estudo, nos domicílios convivem de duas a quatro gerações, portanto as fases se interagem e, muitas vezes, as famílias realizam simultaneamente tarefas desenvolvimentais, oferecendo respaldo para que a própria família promova novos arranjos para o desempenho dos papéis correspondentes a mais que uma fase. No tocante aos vínculos, as famílias referiram apresentar vínculos fortes, exceto na Família 3, em que o filho adolescente apresentava vínculos fragilizados com os demais membros da família e, embora buscasse independência psicológica, precisava manter a convivência com os pais e irmão, mesmo que conflituosa, devido à dependência financeira.

\section{Avaliação funcional}

Dentro do processo de avaliação funcional, a avaliação instrumental permitiu constatar que as famílias possuíam apoio de outros membros da família durante as intercorrências, além da distribuição das tarefas cotidianas, o que facilitou o enfrentamento e reorganização familiar desde a descoberta da doença.

A respeito do funcionamento expressivo, as crenças religiosas e espiritualidade, especificamente, se configuraram elementos facilitadores no processo de aceitação e enfrentamento da doença.

Observou-se, na avaliação expressiva, que as famílias desenvolviam uma comunicação efetiva entre seus elementos, ou seja, cada um compreendia e considerava a mensagem do outro. Todavia, no caso da Família 3, a comunicação era difícil com filho usuário de substâncias psicoativas.

No quesito solução de problemas, as famílias avaliadas demonstraram empoderamento diante da doença/tratamento devido a vivências anteriores, apresentaram capacidade dinâmica e eficaz de resolver problemas, utilizando-se dos recursos disponíveis em cada contexto familiar e social.

\section{DISCUSSÃO}

Sobre a estrutura das famílias estudadas, duas eram constituídas por pessoas em segundo casamento, outras duas eram do tipo estendida e três eram monoparentais - ou seja, novas configurações familiares. A literatura destaca que mudanças no âmbito socioeconômico e cultural vêm interferindo na estrutura e dinâmica familiares, permitindo variações em seu padrão tradicional de organização. Destarte, há o surgimento de novas configurações, decorrentes do número crescente de divórcios, novos casamentos e aumento do número de famílias ampliadas e monoparentais ${ }^{(12)}$.

Em relação a isso, com a redução da família nuclear tradicional, torna-se primordial que o enfermeiro expanda o conceito de família, a fim 
de abarcar novas configurações familiares e os sistemas mais amplos (pessoas externas à família representam um apoio legítimo aos resultados das decisões de tratamento, conduta clínica e comportamento paciente-família, como verificado neste estudo), tendo em vista a ampliação da rede de suporte do grupo familiar para um cuidado efetivo e integral ${ }^{(2,13)}$.

Neste estudo, observou-se que metade das famílias enfrentou o óbito de um de seus membros em decorrência do câncer de mama - o que, na ocasião do falecimento, causou grande sofrimento e o fortalecimento dos laços familiares, fatores muito importantes para amenizar os sentimentos de medo, perda, tristeza, angústia e impotência.

Os relacionamentos familiares se tornaram mais solidificados, constituindo fonte de apoio, segurança e estabilidade emocional. A capacidade de adaptação às demandas dos diferentes níveis de subsistemas vai sendo desenvolvida por cada membro da família. Corroborando com estes resultados, uma pesquisa efetuada no contexto familiar de mulheres diagnosticadas com neoplasia maligna afirmou que todos os membros se mobilizam para acolher, confortar, cuidar e acompanhar a mulher em sua trajetória com a doença oncológica, fortalecendo os laços familiares $^{(14)}$.

Nesta perspectiva, outro estudo, realizado com famílias que possuíam um integrante com neoplasia maligna, apontou que o enfrentamento foi possível nas famílias que conseguiram resgatar os sentimentos positivos e organizaram a rotina familiar. Apesar de a doença mostrar as fragilidades do enfermo e do grupo familiar, a força conjunta venceu as dificuldades e levou ao cultivo de maior amor, respeito e gratidão entre seus membros ${ }^{(15)}$. A habilidade da família de se adaptar à enfermidade de um de seus membros está diretamente ligada à composição, aos padrões de comunicação e à dinâmica familiar ${ }^{(15-16)}$.
Todavia, verificou-se que algumas vezes o familiar projetou os pensamentos além do momento presente e visualizou que as possibilidades que o amanhã lhe reserva podem ser sofridas, pois os planos para o futuro ficaram ameaçados de não acontecer, como foi relatado em duas famílias o temor da morte de suas mães.

Tanto o significado que os familiares conferem ao câncer (como uma doença que os colocam próximos da finitude) quanto o medo da recidiva podem ser aterrorizantes, ou seja, o significado de câncer como sinônimo de morte fica, muitas vezes, instituído em seus sentimentos e interpretações ${ }^{(16)}$ após vivenciá-lo em sua família.

O impacto do diagnóstico de mais um elemento da família com câncer foi ressaltado na avaliação estrutural interna, externado pelas mulheres com a doença oncológica e por seus familiares, não apenas pela gravidade da enfermidade, mas, sobretudo, pelo já vivenciado. Assim, todos os participantes trouxeram à tona que, muitas vezes, escondem seus medos, choros, incertezas, evitando falar sobre a doença, para que aparentem ser destemidos, sobretudo com a mulher mastectomizada.

Para enfrentar a doença, a família necessita de apoio. É o momento de buscar ajuda na comunidade, na igreja e nas instituições envolvidas. Nessa lógica, o enfermeiro tem uma função essencial, mas para proporcionar apoio, inicialmente, precisa compreender como a doença oncológica mobiliza toda a dinâmica familiar e, a partir daí, planejar e direcionar uma assistência abrangente, porém individualizada e com qualidade, a fim de contribuir para o enfrentamento eficaz da doença para cada elemento do núcleo familiar.

Cabe ressaltar que todas as famílias dispunham de múltiplos elementos de apoio advindos do suprassistema familiar, ou seja, amigos, vizinhos, parentes, serviços de saúde, igreja. $\mathrm{Na}$ 
avaliação estrutural de contexto, observou-se que a classe social/condição financeira não influenciou na qualidade do cuidado dispensado as mulheres mastectomizadas - que, inclusive, moravam em bairros com condições sanitárias e sociais satisfatórias.

Segundo a literatura científica, a fundamental fonte de ajuda e apoio das pessoas com câncer são seus familiares; todavia a rede social, constituída por indivíduos que podem apoiar a pessoa, como os amigos e os vizinhos, igualmente é apontada como fundamental e imprescindível para suplantar as dificuldades ${ }^{(14-15)}$.

Destacou-se a busca por suporte espiritual narrada pelas mulheres com mastectomia e pela maioria de seus familiares. A fé/espiritualidade foi um apoio importante na construção dos significados, no fortalecimento para superar os obstáculos, no conforto e na manutenção da esperança, pois se tornou uma ferramenta de suporte. Confirmando estes dados, um estudo apontou que a fé auxiliou a pessoa a confiar em uma força superior e ajudou a manter a esperança ${ }^{(16)}$. A espiritualidade e a fé contribuem para uma forma de pensar construtiva e para o desenvolvimento de um sentimento de confiança de que sempre acontecerá o melhor ${ }^{(1,16)}$.

Efetivamente, a fé é um sentimento enraizado na cultura e tão indispensável quanto outras formas de enfrentamento de uma condição crônica ${ }^{(15-16)}$, como a neoplasia maligna de mama. A espiritualidade é um assunto que vem atraindo a atenção dos profissionais da saúde no que tange o cuidado integral. Pesquisas recentes explanam que este pode ser uma alternativa para melhorar a qualidade de vida das pessoas, além de acelerar o processo de cura e/ou enfrentamento das doenças ${ }^{(15-16)}$.

O vínculo se configurou por intermédio das ligações afetivas e de proximidade que, na maioria das vezes, estava presente nas demonstrações de carinho e afeto durante os encontros com cada família estudada; a harmonia esteve presente e transpareceu nos atos e nas falas de todos os membros entrevistados.

As crenças, os valores, os comportamentos assimilados com os vínculos e o convívio social vislumbraram experiências de vida que o indivíduo e a família foram adquirindo ao longo do processo saúde/doença e no autocuidado(1). A partir desse pressuposto, o enfermeiro precisa compreender a família, acolhendo e reconhecendo suas experiências a fim de mobilizar a investigação de novos conhecimentos e formas de aprendizagem para o exercício do cuidado com os familiares enfermos, destacando que a prioridade é a pessoa e sua família e não o enfermeiro. Para isso, necessitará sempre se qualificar, além de humanizar o atendimento prestado ${ }^{(1,3,14)}$.

As famílias relataram ter uma comunicação efetiva entre seus membros, ou seja, cada um compreendia e respeitava a mensagem do outro. Contudo, em uma das famílias a comunicação era complicada com o filho usuário de substâncias psicoativas. A literatura científica aponta que, quando o uso compulsivo de substâncias psicoativas ocorre, ele tem um impacto não apenas na pessoa que usa, mas sobre o ciclo vital da família, podendo inclusive levar ao congelamento da passagem de uma fase evolutiva para outra.

A família com o filho usuário foi encaminhada para um grupo de orientação familiar, cuja finalidade versava em criar um espaço de reflexão e questionamento não só para as questões relacionadas ao consumo de drogas, como também, sobre a vida familiar e pessoal de cada integrante. Tal atitude foi pautada na premissa que as sessões com grupos de orientação e aconselhamento têm obtidos bons resultados, pois os familiares não se sentem sozinhos ao trocarem experiências com pessoas que passam pelos mesmos problemas num ambiente de afeto e apoio(17). 
Foi notório perceber que os processos que envolvem o câncer levam a várias adaptações, tanto na vida das mulheres mastectomizadas quanto na de sua família, a compreensão dessa vivência torna-se importante para o planejamento de intervenções de enfermagem adequadas a cada integrante da família.

Assim, a imprevisibilidade do curso da neoplasia maligna pode trazer novas imposições e conflitos, o enfermeiro tem como papel avaliar as mudanças ao longo do curso da neoplasia maligna que poderão interferir no contexto familiar, a fim de assistirem as mulheres com câncer de mama e sua família, no direcionamento de ações a serem implementadas e no apoio à superação de cada situação.

\section{CONCLUSÃO}

A avaliação familiar pautada no modelo Calgary possibilitou conhecer as famílias e levantar os fundamentais aspectos da sua estrutura, desenvolvimento e funcionamento. Sabe-se que um dos grandes potenciais de atenção no domicílio é a capacidade de proporcionar suporte e de fortalecer as famílias, dentro das suas especificidades, para lidar com circunstâncias críticas como o câncer de mama, de forma a minimizar o sofrimento e a sobrecarga.

Acredita-se que os resultados deste estudo possam ser usados pelos enfermeiros para subsidiar o planejamento do trabalho no cuidado as mulheres mastectomizadas e sua família.

A limitação deste estudo está relacionada ao método qualitativo, que não permite generalização dos resultados ou estabelecimento de relações de causa e efeito. Outra limitação foi a não possibilidade de entrevistar todas as mulheres sobreviventes com câncer de mama das famílias, a fim de ampliar a percepção sobre o momento vivido, devido a morarem em estados longínquos do país ou mesmo no exterior.

\section{REFERÊNCIAS}

1. Radavanovic CAT, Cecilio HPM, Marcon SS. Structural, developmental and functional evaluation of the family of individuals with arterial hypertension. Rev Gaúcha Enferm. 2013;34(1):45-54.

2. Silva L, Bousso RS, Galera SAF. Aplicação do Modelo Calgary para avaliação de famílias de idosos na prática clínica. Rev bras enferm. 2009; 62(4): 530-34.

3. Cecilio HPM, Santos KS, Marcon SS. Calgary Model of Family Assessment: experience in a community service project. Cogitare enferm. 2014; 19(3):536-44

4. Mavaddat N, Pharoah PD, Blows F, Driver KE, Provenzano $E$, Thompson D, et al. Familial relative risks for breast cancer by pathological subtype: a population-based cohort study. Breast Cancer Res. 2010;12(1):R10.

5. GozzoTO, Lopes RR, Prado MAS, Cruz LAP, Almeida AM. Informações para a elaboração de um manual educativo destinado às mulheres com câncer de mama. Esc. Anna Nery. 2012;16(2):30611.

6. Alves PC, Santos MCL, Fernandes AFC. Stress and coping strategies for women diagnosed with breast cancer: a transversal study. Online Braz J Nurs [internet]. 2012 Aug[cited 2015 June 03];11(2):305-18.Available from: http://www. objnursing.uff.br/index.php/nursing/article/ view/3714/html

7. Wright LM, Leahey M. Enfermeiras e famílias: um guia para avaliação e intervenção na família. $5^{\mathrm{a}}$ ed. São Paulo: ROCA; 2012.

8. Yin RK. Case study research: design and methods. 4 ed. Thousand Oaks: Sage; 2009.

9. Nappo SA, Sanchez ZVDM, Oliveira LG. Crack, AIDS, and women in São Paulo, Brazil. Subst Use Misuse. 2011; 46(4):476-85.

10. Fereday J, Muir-Cochrane E. Demonstrating rigor using thematic analysis: a hybrid approach of inductive and deductive coding and theme development. Int J Qualit Methods [internet]. 
2006 [cited 2015 June 03]5(1). Available from: https://www.ualberta.ca/ iiqm/backissues/5_1/ PDF/FEREDAY.PDF

11. Mendes-Castillo AMC, Bousso RS, Silva LR. Family management for transplantation children patients with grandparents as caregivers: a case study. Online Braz J Nurs [internet]. 2014 Sep[cited 2015 June 03];13(4):667-76. Available from:http:// www.objnursing.uff.br/index.php/ nursing/article/view/4752

12. Leone ET, Maia AG, Baltar PE. Mudanças na composição das famílias e impactos sobre a redução da pobreza no Brasil. Economia e Sociedade. 2010; 19(1):59-77.

13. Elsen I, Souza AIJ, Marcon SS. Enfermagem à família: dimensões e perspectivas. Maringá: Eduem; 2011.

14. Salci MA, Marcon SS. Enfrentamento do Câncer em Família. Texto Contexto Enfermagem. 2011; 20(Esp):178-86.

15. Ferreira NML, Dupas G, Costa DB, Sanches KOL. Câncer e família: compreendendo os significados simbólicos. Cienc Cuid Saude. 2010 Abr-Jun;9(2):269-77.

16. Rocha NS, Fleck MPA. Avaliação de qualidade de vida e importância dada à espiritualidade/ religiosidade/crenças pessoais (SRPB) em adultos com e sem problemas crônicos de saúde. Rev Psiq Clín. 2011;38(1):19-23.

17. Oliveira LG, Ponce JC, Nappo SA. Crack cocaine use in Barcelona: a reason of worry. Subst Use Misuse. 2010;45(1):2291-300.
Todos os autores participaram das fases dessa publicação em uma ou mais etapas a seguir, de acordo com as recomendações do International Committe of Medical Journal Editors (ICMJE, 2013): (a) participação substancial na concepção ou confecção do manuscrito ou da coleta, análise ou interpretação dos dados; (b) elaboração do trabalho ou realização de revisão crítica do conteúdo intelectual; (c) aprovação da versão submetida. Todos os autores declaram para os devidos fins que são de suas responsabilidades o conteúdo relacionado a todos os aspectos do manuscrito submetido ao OBJN. Garantem que as questões relacionadas com a exatidão ou integridade de qualquer parte do artigo foram devidamente investigadas e resolvidas. Eximindo, portanto o OBJN de qualquer participação solidária em eventuais imbróglios sobre a materia em apreço. Todos os autores declaram que não possuem conflito de interesses, seja de ordem financeira ou de relacionamento, que influencie a redação e/ou interpretação dos achados. Essa declaração foi assinada digitalmente por todos os autores conforme recomendação do ICMJE, cujo modelo está disponível em http://www. objnursing.uff.br/normas/DUDE_final_13-06-2013.pdf

Recebido: 08/06//2015

Revisado: 20/02/2016

Aprovado: 20/02/2016 